Cartas al Director

\title{
Leucemia secundaria al tratamiento del carcinoma testicular
}

\section{Sr. Director:}

El cáncer testicular incide fundamentalmente en pacientes jóvenes, habitualmente el pronóstico es excelente, cifrándose en más del $95 \%$ los pacientes que están vivos a los 5 años del diagnóstico'.

Los tumores relacionados con la quimioterapia en esta neoplasia, representan un problema pequeño pero importante, así el riesgo para desarrollar un segundo tumor relacionado con la quimioterapia previa es de 2 a 3 veces mayor comparado con la población general $^{2}$.

La mayoría de los fármacos citostáticos son dependientes del ciclo celular, así las toxicidades agudas se relacionan con la cinética proliferativa de poblaciones celulares determinadas. Los órganos o tejidos más susceptibles serán aquellos que muestren una tasa de división alta, como son la médula ósea, mucosas, testículo e hígado; por el contrario aquellos cuya replicación celular es mínima o inexistente (neuronas y músculo) serán los menos susceptibles.

Presentamos un caso de leucemia aguda promielocítica en un varón que un año y medio antes recibió tratamiento de quimioterapia por un carcinoma testicular.

Varón de 21 años de edad, hace dieciocho meses denotó aumento del tamaño del testículo izquierdo. Se realizó una ecografía que fue informada de alta sospecha de neoplasia del teste izquierdo. Los marcadores tumorales se encontraron elevados, así la alfa fetoproteína fue de $341 \mathrm{ng} / \mathrm{ml}$ y la beta hormona gonadotropina coriónica de $307 \mathrm{UI} / \mathrm{L}$.

Se efectúo una orquidectomía izquierda por vía inguinal. El informe de anatomía patológica fue de carcinoma embrionario, sin afectación del cordón ni de la albugínea. El estudio de extensión mostró una serie ósea normal, tomografía axial computarizada tóracoabdominal normal. Fue diagnosticado de tumor testicular no seminomatoso estadio IM, administrándose tratamiento de quimioterapia con esquema BEP (bleomicina a dosis de 30 unidades los días 1 y 8 , etoposido a dosis de $175 \mathrm{mg}$ por cinco días y cisplatino 35 $\mathrm{mg}$ por cinco días). Se dieron dos ciclos de quimiote- rapia y posteriormente siguió revisiones periódicas en la consulta de oncología, permaneciendo asintomático y $\sin$ datos de recidiva en las pruebas que se efectuaron. En una revisión efectuada a los 16 meses del diagnóstico, el hemograma era normal: 6000 leucocitos con 3600 neutrófilos, hemoglobina de 16 gramos /dl y 228.000 plaquetas. Consultó nuevamente cuarenta y cinco días después al denotar lesiones equimóticas y ulceradas en la mucosa bucal, también presentaba hematomas y equimosis en el tronco y extremidades inferiores sin relacionarse con traumatismos. No presentaba fiebre ni otra sintomatología ni existía hiperplasia gingival. Se le realizó un hemograma en el que se objetivaron 65.000 leucocitos con un $56 \%$ de blastos de aspecto monocitoide; hemoglobina de 12,8 gramos/dl y 17.000 plaquetas. Actividad de protrombina del $75 \%$ y fibrinógeno de $213 \mathrm{mg} / \mathrm{dl}$.

Fue diagnosticado de leucemia aguda promielocíti$\mathrm{ca}$, remitiéndose al paciente a otro centro, pero a las 24 horas presentó datos hematológicos compatibles con una coagulación intravascular diseminada (CID), entrando súbitamente en coma neurológico. En una TAC craneal se objetivaron 3 focos de sangrado intracerebral, falleciendo pocas horas más tarde.

Las leucemias secundarias al tratamiento del cáncer testicular tienen una elevada mortalidad ${ }^{3}$ y dado que el carcinoma testicular tiene una incidencia creciente, es un dato que hay que tener muy en cuenta ${ }^{4}$.

La leucemia relacionada con la quimioterapia es muy poco frecuente, se ha asociado al uso de inhibidores de la topoisomerasa II y de agentes alquilantes ${ }^{2}$.

Se ha observado que citostáticos con diverso mecanismo de acción, pueden tener un efecto sinérgico en la leucemogénesis, así ocurre con el cisplatino al unirse directamente con el DNA y el etoposido al realizar la inhibición de la topoisomerasa $\|^{5}$.

Las características de las leucemias agudas que se desarrollan secundariamente al tratamiento de quimioterapia con agentes alquilantes, presentan un período de latencia de 4-6 años, siendo los fenotipos más frecuentes los M6 y M7. En cuanto a los inhibidores de la topoisomerasa presentan un período de latencia de 1 
a 3 años, siendo los fenotipos más frecuentes los M4 y M5 de la clasificación FAB.

En la mayoría de los casos el efecto cancerígeno depende de la dosis total acumulada y del calendario de administración. Así los pacientes con cáncer testicular que reciben una dosis acumulada de cisplatino inferior a 650 miligramos tienen un riesgo estimado de sufrir una leucemia secundaria del $3,2 \%$. Por su parte con el etoposido a dosis acumuladas entre 1500 y 2999 miligramos, tiene un riesgo de leucemia secundaria de $0,7 \%$

Cuando se pone en una balanza el riesgo de desarrollar una leucemia aguda secundaria al tratamiento con las ventajas que aporta la radioterapia y la quimioterapia en el tratamiento del carcinoma testicular, la mejoría sustancial en la supervivencia excede con mucho a los prejuicios; pero el riesgo bajo pero no despreciable de leucemias secundarias a la quimioterapia, debe animarnos a buscar quimioterapias igualmente eficaces pero con menor toxicidad.

\section{S. Casallo Blanco, F. Solano Ramos*, F. Marcos Sánchez, A. Viana Alonso, F. Juárez Ucelay Servicios de Medicina Interna y de Hematología* Hospital № Sa del Prado Talavera de la Reina (Toledo)}

\section{Bibliografía}

1. Papworth DG, Lloyd RA. Cancer survival in the USA 1973-1990, a statical analysis. Br J Cancer 1998; 78: 1514-1515.

2. Kollmannsberger C, Kuzyk M, Mayer F, Hartmann JT, Kanz L, Bokemeyer C. Late toxicity following curative treatment of testicular cancer. Semin Surg Oncol 1999; 17: 275-281.

3. Travis LB, Curtis RE, Storm H, Hall P, Holowaty E, Van Leeuwen FE. Risk of second malignant neoplasms among long-term survivors of testicular cancer. J Natl Cancer Inst 1997; 89: 1429-1439.

4. Buestow SA. Epidemiology of testicular cancer. Epidemiol Rev 1995; 17: 433-449.

5. Pedersen Bjergaard J, Rowley JD The balanced and the unbalanced chromosome aberrations of acute myeloid leukemia may develop in different ways and may contribute differently to malignant transformation. Blood 1994; 83: 2780-2786.

6. Travis LB, Anderson M, Gospodarowicz M, Van Leeuwen FE, Bergfeldt K, Lynch CF. Treatment-associated leukemia following testicular cancer. J Natl Cancer Inst 2000; 92: 1165-1171.
Correspondencia: Dr. F. Marcos Sánchez Escosura, 4 - 6음 E-28015 Madrid 